Tropical Journal of Pharmaceutical Research June 2015; 14 (6): 1021-1028

ISSN: $1596-5996$ (print); 1596-9827 (electronic)

(C) Pharmacotherapy Group, Faculty of Pharmacy, University of Benin, Benin City, 300001 Nigeria.

All rights reserved.

Available online at http://www.tjpr.org

Original Research Article

http://dx.doi.org/10.4314/tjpr.v14i6.12

\title{
Ameliorative Effects of Neurolytic Celiac Plexus Block on Stress and Inflammation in Rats with Partial Hepatectomy
}

\author{
Jun $\mathrm{Li}^{1}$, Fu-Xiang $\mathrm{Li}^{2}$, Jian-Xiang Che ${ }^{3}$, Xiao-Hong Wei ${ }^{4}$, Qing-Ming Qiu ${ }^{3}$, Peng \\ Zha $^{1}$, Shu-Rong Bai ${ }^{1}$, Xu-Dong Tang ${ }^{5}$ and Tao Chen ${ }^{6 *}$ \\ ${ }^{1}$ Department of Anesthesia, ${ }^{2}$ Department of ICU. Chengdu Military General Hospital, No. 270 Rongdu Avenue, Jinniu District, \\ Chengdu 610083, Sichuan Province, ${ }^{3}$ Department of Anesthesia, The 44th Hospital of PLA, Guiyang 550009, Guizhou \\ Province, ${ }^{4}$ Department of Cardiovascular Surgery, Chengdu Military General Hospital, No. 270 Rongdu Avenue, Jinniu District, \\ Chengdu 610083, Sichuan Province, ${ }^{5}$ Department of Cardiothoracic Surgery, The 44th Hospital of PLA, Guiyang 550009, \\ Guizhou Province, ${ }^{6}$ Department of General Surgery Center, Chengdu Military General Hospital, No. 270, Rongdu Avenue, \\ Jinniu District, Chengdu 610083, Sichuan Province, PR China
}

*For correspondence: Email: taochencz@126.com, xutang44@163.com; Tel: +86 28 86571251; Fax: +86 2886570421

Received: 26 December 2014

Revised accepted: 14 May 2015

\begin{abstract}
Purpose: To investigate effects of neurolytic celiac plexus block (NCPB) on stress and inflammation in rats with partial hepatectomy $(\mathrm{PH})$.

Methods: $A$ model of $P H$ rat was established, and serum C-reactive protein (CRP); corticosterone (GC); adrenocorticotropin (ACTH); noradrenaline (NA); adrenalin (AD); aspartate transaminase (AST); alanine transaminase (ALT); as well as tumor necrosis factor- $\alpha$ (TNF- $\alpha$ ); interleukin (IL)-1 $\beta$ and IL-6; high mobility group box1 (HMGB1); and nitric oxide (NO) concentrations in serum assessed after PH. Additionally, Western blotting was performed to determine the effect of NCPB on expressions of glucocorticoid receptors (GR), inhibitor of nuclear factor kappa B (IKB), p65, c-Jun and inducible nitric oxide synthase (iNOS) of PH rats, as well as assay effects of NCPB on nuclear translocation of GR, cJun and p65. DNA binding activities of nuclear factor kappa B (NF-KB) and activator protein 1 (AP-1) were also determined.

Results: NCPB reduced AST and ALT $(P<0.05)$, decreased secretion of inflammatory cytokines and NO $(P<0.05)$, as well as decreased CRP, GC, ACTH, NA and AD after PH $(p<0.05)$. NCPB increased expressions of GR and IKB, but expressions of $p 65, c-J u n$, and iNOS $(p<0.05)$. Additionally, NCPB increased nuclear translocation of GR $(p<0.01)$, but decreased nuclear translocation of $p 65$ and $c-J u n$ after PH $(p<0.05)$. Additionally, DNA binding activity of NF-KB and AP-1 was decreased by NCPB $(p<$ 0.05).

Conclusion: The results indicate that NCPB treatment can significantly inhibit stress and inflammation in $\mathrm{PH}$ rats.
\end{abstract}

Keywords: Neurolytic celiac plexus block, Cytokine, Nuclear translocation, Partial hepatectomy, Stress, Inflammation

Tropical Journal of Pharmaceutical Research is indexed by Science Citation Index (SciSearch), Scopus, International Pharmaceutical Abstract, Chemical Abstracts, Embase, Index Copernicus, EBSCO, African Index Medicus, JournalSeek, Journal Citation Reports/Science Edition, Directory of Open Access Journals (DOAJ), African Journal Online, Bioline International, Open-J-Gate and Pharmacy Abstracts

\section{INTRODUCTION}

Autonomic nervous system (ANS) plays important roles in stress and inflammatory reaction after severe trauma [1,2]. The parasympathetic nervous system (PNS) can regulate the inflammatory reactions effectively through acetylcholine [3]. Solar plexus, the largest human autonomic plexuses, consisted of sympathetic nerve, parasympathetic nerve and 
sensory nerve. Moreover, the solar plexus play crucial effects on regulation the functions of organ in epigastric region including liver, guts, pancreas, etc. Neurolytic celiac plexus block (NCPB) has been used for treating pain of pancreatic diseases for very long time, and is widely performed to treat visceral pain related to retroperitoneal and metastatic tumors [4-7].

Severe trauma can induce strong stress and inflammatory reactions, leading to over-activation of inflammatory cascade reaction, even the systemic inflammatory response syndrome (SIRS) [8,9]. The SIRS is one of the major causes of multiple organ dysfunction syndrome (MODS) as well as death. Thus, it's important to alleviate the damages of severe liver trauma and liver cancer surgery in order to suppress or control the levels of stress and inflammatory reaction. In our previous investigation, we found that NCPB can improve the liver regeneration after $\mathrm{PH}$, as well as decrease the proinflammatory cytokines in serum [10]. As a part of our continuing investigation of NCPB, this study was designed to investigate the ameliorative effects of NCPB on stress and inflammation in $\mathrm{PH}$ rats.

\section{EXPERIMENTAL}

\section{Chemicals and Regents}

Corticosterone (GC) ELISA Kit, Adrenocorticotropin (ACTH) ELISA Kit, Noradrenaline (NA) ELISA Kit, Adrenalin (AD) ELISA Kit, Trans AM $^{\text {TM }}$ NF-KB p65 kit, Trans $\mathrm{AM}^{\mathrm{TM}}$ AP-1 c-Jun kit were purchased from the Beijing north institute of Biological Technology (Beijing, China); Rat TNF- $\alpha$ ELISA kit, Rat IL-1 $\beta$ ELISA kit, Rat IL-6 ELISA kit, Rat C-Reactive Protein (CRP) ELISA kit were purchased from Cusabio Life Science Ltd. (Wuhan, China); Rat HMGB1 ELISA Kit was purchased from Biovendor R\&D (Shanghai, China); Nitric Oxide assay kit was purchased from the Nanjing Jiancheng Bioengeering Institute (Nanjing, China); Cell protein extracts and Nuclear protein extracts were purchased from Pierce Protein Biology (Rockford, USA); Anti-GR rabbit polyclonal IgG, Anti-NF-kB p65 rabbit polyclonal IgG, Anti-NF-KB p65 rabbit polyclonal IgG, Anti-cJun rabbit polyclonal IgG, Anti- $\beta$-Actin rabbit polyclonal IgG, Anti- Lamin B rabbit polyclonal IgG were purchased from the Santa Cruz Biotech, Inc. (California, USA). The Rabbit antigoat IgG/HRP and Goat anti-rabbit IgG/HRP were obtained from Zhongshan Biotech Co. Ltd. (Guangdong, China). SDS-PAGE Molecular high weight markers for proteins were purchased from the Shanghai Lizhudongfeng Biotech Ltd. (Shanghai, China). The prestained protein molecular weight marker was purchased from Xian Runde Biotech Ltd. (Xian, China). All other chemicals used in this study were of analytical reagent grade.

\section{Ethics statement}

All animal treatments were strictly in accordance with international ethical guidelines and the National Institutes of Health Guide concerning the Care and Use of Laboratory Animals, and the experiments were carried out with the approval of the Animal Experimentation Ethics Committee of the General Hospital of Chengdu Military Command Area (No. CDZYY2012KX25).

\section{Animals}

The animals were provided by the medical laboratory animal center of the Third Military Medical University and followed the Principles of Laboratory Animal Care [11]. Male SpragueDawley rats, weighing $200 \pm 20 \mathrm{~g}$, were used in our study. Rats were kept on a 12-h light/dark cycle with free access to standard laboratory chow and water. Humidity was maintained at 50 $\%$ and the temperature at $25{ }^{\circ} \mathrm{C}$. Each animal was used only once in the experiment.

\section{Partial hepatectomy}

Our rat $\mathrm{PH}$ model was prepared using the method described previously by Higgins and Anderson [12,13] with minor modifications. In brief, approximately $70 \%$ of the liver (left and middle hepatic lobe) was surgically removed. Rats were anesthetized with sodium pentobarbital (40 mg/kg, ip). Thereafter, the left and medial lobes of liver were resected after a midline laparotomy. Subsequently, the abdominal wound was closed.

\section{Neurolytic celiac plexus block}

The method to achieve percutaneous NCPB in rats was performed as described previously [14], with minor modifications. In brief, $0.5 \%$ xylocaine was injected once the needle tip reached the anatomic site of the celiac plexus once per day, over a total of 7 days. For the control group, rats underwent the same surgical procedure, but physiological saline was injected instead of $0.5 \%$ xylocaine.

\section{Experimental design}

A total of 30 rats underwent $\mathrm{PH}$ as described above, and the rats were equally divided into the 
following two groups ( $n=15)$ : (1) Control group, and (2) NCPB-treated group. For the NCPBtreated group, percutaneous NCPB was performed with $0.5 \%$ xylocaine after $\mathrm{PH}$. Five rats were used to collect blood and liver tissues at each time point $(1,3$, and 7 days), [under pentobarbital sodium $(60 \mathrm{mg} / \mathrm{kg})]$ after percutaneous NCPB. The serum samples were separated by natural deposition, and were stored at $-70{ }^{\circ} \mathrm{C}$ until further analysis. Additionally, the peritoneal macrophage was collected following the method described previously [15], and the cells were cultured in 6 pore plate containing DMEM supplemented with $10 \%$ heat-inactivated FBS for $24 \mathrm{~h}$ (at $37{ }^{\circ} \mathrm{C}$ with $5 \% \mathrm{CO}_{2}$ ) for further investigations.

\section{Determination of the biochemical indicators of serum}

The serum corticosterone (GC), adrenocorticotropin (ACTH), noradrenaline (NA), adrenalin $(A D)$, aspartate transaminase (AST), alanine transaminase (ALT), CRP, TNF- $\alpha, I L-1 \beta, I L-6$ HMGB1 concentrations in serum were determined by ELISA and quantified using a microplate reader (Bio-Tek ELX800) at $450 \mathrm{~nm}$ with commercial kits.

\section{Determination of the NO production}

The method of nitrate reductase (Griess method) was performed to determine the total contents of $\mathrm{NO}_{3}{ }^{-}$and $\mathrm{NO}_{2}{ }^{-}$(which can be used to evaluate the NO levels in serum), based on the instructions of commercial nitric oxide assay kits [13]. Briefly, following the introduction of the commercial kit, serum samples $(100 \mu \mathrm{L})$ was added to $100 \mu \mathrm{L}$ Griess reagents, and incubated at room temperature for $10 \mathrm{~min}$; then absorbance of the mixture measured at $540 \mathrm{~nm}$, and calculated the contents of nitrites based on the standard curve of standard solution.

\section{Western blotting}

Cells were harvested, and the total protein/nucleoprotein was extracted, and equal amounts of protein $(50 \mu \mathrm{g})$ were separated by SDS-PAGE, blotted on polyvinylidene difluoride membranes, and probed with Anti-GR rabbit polyclonal IgG, Anti-NF-kB p65 rabbit polyclonal IgG, Anti-NF-KB p65 rabbit polyclonal IgG, Anti-CJun rabbit polyclonal IgG, Anti- $\beta$-Actin rabbit polyclonal IgG, Anti- Lamin B rabbit polyclonal IgG, following by incubation with a goat antirabbit/HRP secondary antibody, and detected by chemiluminescence. To measure protein loading, antibodies directed against $\beta$-Actin and Lamin B were used.

\section{Determination of the DNA binding activities of NF-KB and AP-1}

The nucleoprotein of the peritoneal macrophage was isolated. Then, the DNA binding activities of $\mathrm{NF}-\mathrm{kB}$ and AP-1 were determined as the introductions of the commercial kits and quantified using a microplate reader (Bio-Tek ELX800) at $450 \mathrm{~nm}$.

\section{Statistical analysis}

All the experiments were conducted at least in triplicate, and the data presented as mean \pm SD. The statistical significance of differences was analyzed by using SPSS software (SPSS for Windows 18.0, SPSS Inc., USA), and performed using the two-tailed Student's $t$ test with a significance level of $p<0.05$.

\section{RESULTS}

\section{Effect of NCPB on functions of liver and kidney of rats after $\mathrm{PH}$}

As can be seen from the Table 1, the levels of aspartate aminotransferase (AST) and alanine aminotransferase (ALT) of the control and NCPB groups were all decreased gradually; the AST and ALT levels of the NCPB mice group at 1, 3 and 7 days after $\mathrm{PH}$ were significantly lower than that in the control group mice $(p<0.05)$. In addition, the levels of creatinine $(\mathrm{Cr})$ and blood urea nitrogen (BUN) of the NCPB mice group at 1 and 3 days after $\mathrm{PH}$ were also significantly lower than that in the control group mice $(p<$ 0.05 ). The results of our present study indicated that the NCPB can improve the functions of liver and kidney of rats after $\mathrm{PH}$ surgery.

\section{Effect of NCPB on the CRP, GC, ACTH, NA, and $A D$ in serum of rats after $P H$}

The concentration of CRP was measured in the serum of rats after $\mathrm{PH}$ (Table 2). The results indicated that CRP level increased until 3rd days after $\mathrm{PH}$, and then decreased until the 7th day after $\mathrm{PH}$. However, the serum concentration of CRP in the NCPB group was significantly lower significantly than that of the control group at each time point $(p<0.05)$. Furthermore, the concentrations of the GC, ACTH, NA, and $A D$ in serum of rats after $\mathrm{PH}$ were also determined, and our results suggested that the levels of these biochemical indicators were all progressively decreased until the end of the observation period in both the control and NCPB groups; 
Table 1: Effect of NCPB on functions of liver and kidney of rats after PH $(n=5$, mean \pm SD)

\begin{tabular}{|c|c|c|c|c|c|}
\hline Parameter & & & Day 1 & Day 3 & Day 7 \\
\hline \multirow{4}{*}{$\begin{array}{l}\text { Liver functions } \\
(\mathrm{U} / \mathrm{L})\end{array}$} & \multirow{2}{*}{ AST } & Control & $927.4 \pm 82.6$ & $558.6 \pm 51.2$ & $214.8 \pm 19.3$ \\
\hline & & NCPB & $509.1 \pm 46.1^{b}$ & $256.6 \pm 24.6^{a}$ & $154.3 \pm 14.9^{a}$ \\
\hline & \multirow{2}{*}{ ALT } & Control & $474.1 \pm 38.3$ & $112.5 \pm 11.9$ & $43.9 \pm 3.5$ \\
\hline & & NCPB & $361.0 \pm 27.0^{a}$ & $78.5 \pm 6.3^{b}$ & $41.6 \pm 3.1$ \\
\hline \multirow{4}{*}{$\begin{array}{l}\text { Kidney functions } \\
(\mu \mathrm{mol} / \mathrm{L})\end{array}$} & \multirow{2}{*}{$\mathrm{Cr}$} & Control & $104.6 \pm 8.3$ & $134.5 \pm 11.7$ & $87.3 \pm 7.2$ \\
\hline & & NCPB & $78.2 \pm 6.7^{b}$ & $95.1 \pm 9.4^{b}$ & $79.1 \pm 6.7$ \\
\hline & \multirow{2}{*}{ BUN } & Control & $5.91 \pm 0.44$ & $7.34 \pm 0.64$ & $5.35 \pm 0.43$ \\
\hline & & NCPB & $5.12 \pm 0.38^{a}$ & $5.71 \pm 0.51^{b}$ & $5.24 \pm 0.37$ \\
\hline
\end{tabular}

${ }^{\mathrm{a}} p<0.05 ;{ }^{\mathrm{b}} p<0.01$, compared with the control

despite this similar trend, the serum concentrations of GC, ACTH, NA, and AD in the NCPB group was significantly lower significantly than that of the control group at each time point $(p<0.05)$.

\section{Effect of NCPB on the inflammatory cytokines and NO in serum of rats after $\mathrm{PH}$}

As the results showed in Table 3, the concentrations of inflammatory cytokines and NO in serum of rats after $\mathrm{PH}$ surgery were measured. The concentrations of all the TNF- $\alpha$, IL-6, IL-1 $\beta$ were at their maximum at 1 day after $\mathrm{PH}$, and diminished progressively until the end of the observation period. The serum concentrations of IL-1 $\beta$ and TNF- $\alpha$ in the NCPB group were significantly lower than that of the control group at each time point $(p<0.05)$; additionally, the IL-6 concentration in the NCPB group was significantly lower than that the control group at 1 day after $\mathrm{PH}(p<0.05)$. The serum concentration of HMGB1 was also determined after $\mathrm{PH}$, and the results indicated that HMGB1 concentration of the NCPB group was significantly lower than that of the control group at each time point $(p<0.05)$. Furthermore, the NO levels were determined, and our study demonstrated that the serum NO levels of both the two groups were decreased gradually, however the NO level of the NCPB mice were obviously lower than that of the control mice at 1 and 3 days after $\mathrm{PH}(p<0.05)$.

Table 2: Effect of NCPB on stress index of rats after $\mathrm{PH}(\mathrm{pg} / \mathrm{mL}, n=5$, mean $\pm \mathrm{SD})$

\begin{tabular}{|c|c|c|c|c|}
\hline Parameter & & Day 1 & Day 3 & Day 7 \\
\hline \multirow[t]{2}{*}{$\mathrm{CRP}$} & Control & $552.9 \pm 50.8$ & $723.3 \pm 63.0$ & $383.2 \pm 37.1$ \\
\hline & NCPB & $182.9 \pm 16.8^{b}$ & $342.5 \pm 31.9^{b}$ & $321.9 \pm 31.5^{a}$ \\
\hline \multirow[t]{2}{*}{ GC } & Control & $43.12 \pm 3.45$ & $21.23 \pm 2.02$ & $13.72 \pm 1.13$ \\
\hline & NCPB & $29.31 \pm 2.87^{b}$ & $16.22 \pm 1.56^{\mathrm{D}}$ & $9.82 \pm 0.91^{\mathrm{D}}$ \\
\hline \multirow[t]{2}{*}{$\mathrm{ACTH}$} & Control & $32.72 \pm 3.11$ & $11.62 \pm 1.06$ & $7.22 \pm 0.68$ \\
\hline & NCPB & $13.23 \pm 1.24^{\mathrm{D}}$ & $6.73 \pm 0.49^{D}$ & $3.35 \pm 0.31^{\mathrm{D}}$ \\
\hline \multirow[t]{2}{*}{ NA } & Control & $753.6 \pm 62.4$ & $368.6 \pm 51.0$ & $313.2 \pm 28.8$ \\
\hline & NCPB & $325.4 \pm 29.7^{b}$ & $241.7 \pm 22.1^{b}$ & $267.9 \pm 23.0^{a}$ \\
\hline \multirow[t]{2}{*}{$A D$} & Control & $821.3 \pm 74.2$ & $650.7 \pm 58.1$ & $258.2 \pm 24.5$ \\
\hline & NCPB & $425.6 \pm 39.6^{b}$ & $341.1 \pm 33.2^{b}$ & $198.9 \pm 18.7^{b}$ \\
\hline
\end{tabular}

${ }^{a} p<0.05 ;{ }^{b} p<0.01$, compared with the control

Table 3: Effect of NCPB on inflammatory cytokines and NO of rats after $\mathrm{PH}(n=5$, mean \pm SD)

\begin{tabular}{lcccc}
\hline Parameter & & Day 1 & Day 3 & Day 7 \\
\hline NO & Control & $49.2 \pm 4.5$ & $24.1 \pm 3.1$ & $15.2 \pm 1.2$ \\
$(\mu \mathrm{mol} / \mathrm{L})$ & NCPB & $29.5 \pm 2.3^{\mathrm{a}}$ & $15.0 \pm 1.3^{\mathrm{a}}$ & $13.6 \pm 1.1$ \\
TNF-a & Control & $1823.6 \pm 166.2$ & $1654.0 \pm 129.0$ & $1142.8 \pm 104.1$ \\
$(\mathrm{pg} / \mathrm{mL})$ & NCPB & $1471.8 \pm 133.6^{\mathrm{a}}$ & $1105.4 \pm 98.4^{\mathrm{a}}$ & $861.4 \pm 76.0^{\mathrm{a}}$ \\
$\mathrm{IL}-1 \beta$ & Control & $53.2 \pm 5.2^{\mathrm{a}}$ & $44.5 \pm 3.9^{\mathrm{a}}$ & $34.0 \pm 3.4$ \\
$(\mathrm{pg} / \mathrm{mL})$ & NCPB & $34.6 \pm 3.2^{\mathrm{a}}$ & $29.1 \pm 2.7^{\mathrm{a}}$ & $23.7 \pm 2.1^{\mathrm{a}}$ \\
$\mathrm{IL}-6$ & Control & $21.4 \pm 1.9$ & $13.2 \pm 1.8$ & $10.9 \pm 0.9$ \\
$(\mathrm{pg} / \mathrm{mL})$ & NCPB & $14.3 \pm 1.3^{\mathrm{a}}$ & $11.7 \pm 1.1$ & $9.3 \pm 0.8$ \\
$\mathrm{HMGB} 1$ & Control & $4.13 \pm 0.32$ & $13.25 \pm 1.32$ & $5.02 \pm 0.47$ \\
$(\mathrm{pg} / \mathrm{mL})$ & NCPB & $2.13 \pm 0.14^{\mathrm{a}}$ & $3.11 \pm 0.24^{\mathrm{a}}$ & $3.34 \pm 0.28^{\mathrm{a}}$ \\
\hline
\end{tabular}

${ }^{\mathrm{a}} p<0.05 ;{ }^{\mathrm{b}} p<0.01$, compared with the control 


\section{Effect of NCPB on expressions of GR, IKB, p65, c-Jun, and iNOS in peritoneal macrophage}

The protein expressions of GR, IKB, p65, c-Jun, and iNOS were showed in Figure 1 and Table 4. The protein expression level of GR in the NCPB group was obviously higher than that of control group $(p<0.01)$. Moreover, the c-Jun level was significantly lower than that of control group at 1 and 3 days after $\mathrm{PH}(p<0.01)$. Similar with the $\mathrm{c}-\mathrm{Jun}$, the protein expression levels of p65 and iNOS were significantly lower in the NCPB group compared to the control group at each time point after $\mathrm{PH}(p<0.01)$; whereas the protein expressions of IKB were higher in the NCPB compared with control group at 1 and 3 days after $\mathrm{PH}(p<0.01)$.

\section{Effect of NCPB on nuclear translocation of GR, C-Jun, p65 in peritoneal macrophage}

In our present study, the nuclear translocation of GR was evaluated by determination the protein expressions of GR in ribonucleoprotein. As can be seen from the Figure 2 and Table 5 , the expressions of $\mathrm{GR}$ in ribonucleoprotein of the NCPB group was obviously higher than that of control group at 1 , and 3 days after $\mathrm{PH}(p<$ 0.01 ). Additionally, we determined the p65 and cJun to evaluate the nuclear translocation levels of NF-kB and AP-1. Our present results showed that the levels of c-Jun were significantly lower than that of the control group $(p<.0 .01)$, and the levels of p65 were obviously lower in the NCPB group compared to the control group at each time point after $\mathrm{PH}(p<0.05)$.

Table 4: Effect of NCPB on expressions of GR, IKB, p65, c-Jun, and iNOS (Int $\times \mathrm{mm}^{2}, n=5$, mean \pm SD)

\begin{tabular}{llccc}
\hline Parameter & & Day 1 & Day 3 & Day 7 \\
\hline GR & Control & $1.54 \pm 0.06$ & $1.76 \pm 0.05$ & $1.96 \pm 0.05$ \\
& NCPB & $1.79 \pm 0.06^{\mathrm{b}}$ & $2.22 \pm 0.06^{\mathrm{b}}$ & $2.24 \pm 0.08^{\mathrm{b}}$ \\
C-Jun & Control & $2.41 \pm 0.11$ & $1.54 \pm 0.10$ & $1.48 \pm 0.11$ \\
& NCPB & $0.78 \pm 0.05^{\mathrm{b}}$ & $1.04 \pm 0.09^{\mathrm{b}}$ & $1.43 \pm 0.12$ \\
IKB & Control & $1.93 \pm 0.12^{\mathrm{b}}$ & $1.13 \pm 0.09$ & $1.28 \pm 0.11$ \\
& NCPB & $2.29 \pm 0.14^{\mathrm{b}}$ & $2.01 \pm 0.12^{\mathrm{b}}$ & $1.96 \pm 0.14^{\mathrm{b}}$ \\
p65 & Control & $2.36 \pm 0.13$ & $2.99 \pm 0.18$ & $2.68 \pm 0.16$ \\
& NCPB & $0.76 \pm 0.08^{\mathrm{b}}$ & $0.89 \pm 0.06^{\mathrm{b}}$ & $0.95 \pm 0.08^{\mathrm{b}}$ \\
iNOS & Control & $1.78 \pm 0.11$ & $2.28 \pm 0.16$ & $2.36 \pm 0.19$ \\
& NCPB & $1.49 \pm 0.09^{\mathrm{b}}$ & $1.44 \pm 0.13^{\mathrm{b}}$ & $0.87 \pm 0.04^{\mathrm{b}}$ \\
\hline
\end{tabular}

${ }^{\mathrm{D}} P<0.01$ compared with the control

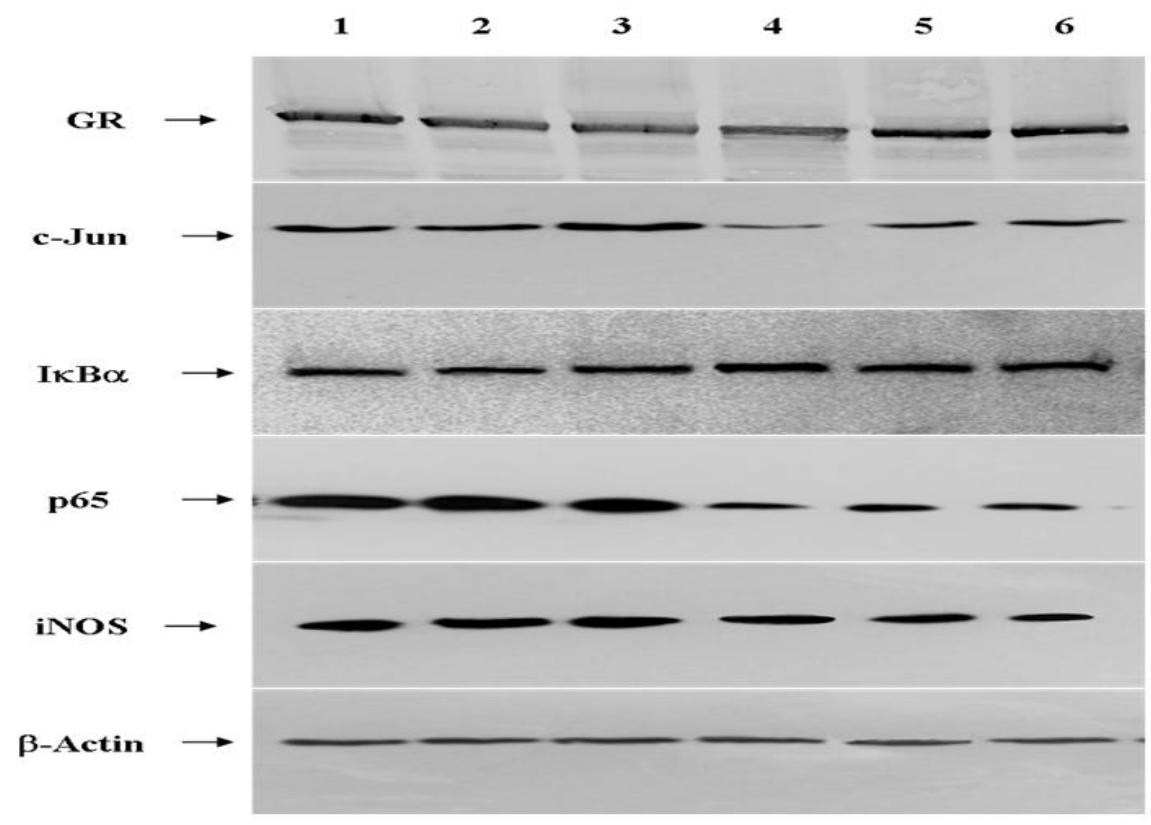

Figure 1: Effects of NCPB on expressions of GR, IKB, p65, c-Jun, and iNOS. Lanes 1-3 represented the protein expressions in the control group at 7, 3 and 1 days after $\mathrm{PH}$, respectively. Lanes 4-6 represented the protein expressions level in NCPB group at 1, 3 and 7 days after $\mathrm{PH}$, respectively 
Table 5: Effect of NCPB on nuclear translocation of GR, c-Jun, p65 (Int $\times \mathrm{mm}^{2}, n=5$, mean \pm SD)

\begin{tabular}{llccc}
\hline Parameter & & Day 1 & Day 3 & Day 7 \\
\hline GR & Control & $0.65 \pm 0.05$ & $0.77 \pm 0.04$ & $1.04 \pm 0.07$ \\
& NCPB & $0.92 \pm 0.08^{\mathrm{b}}$ & $0.95 \pm 0.06^{\mathrm{D}}$ & $1.02 \pm 0.09$ \\
c-Jun & Control & $0.75 \pm 0.06$ & $1.27 \pm 0.10$ & $1.15 \pm 0.09$ \\
& NCPB & $0.83 \pm 0.08$ & $0.71 \pm 0.07^{\mathrm{b}}$ & $0.89 \pm 0.08^{\mathrm{b}}$ \\
p65 & Control & $1.35 \pm 0.12$ & $1.47 \pm 0.11$ & $2.23 \pm 0.18$ \\
& NCPB & $1.15 \pm 0.11^{\mathrm{a}}$ & $0.83 \pm 0.09^{\mathrm{b}}$ & $0.91 \pm 0.05^{\mathrm{b}}$ \\
\hline
\end{tabular}

${ }^{\mathrm{a}} p<0.05 ;{ }^{b} p<0.01$, compared with the control

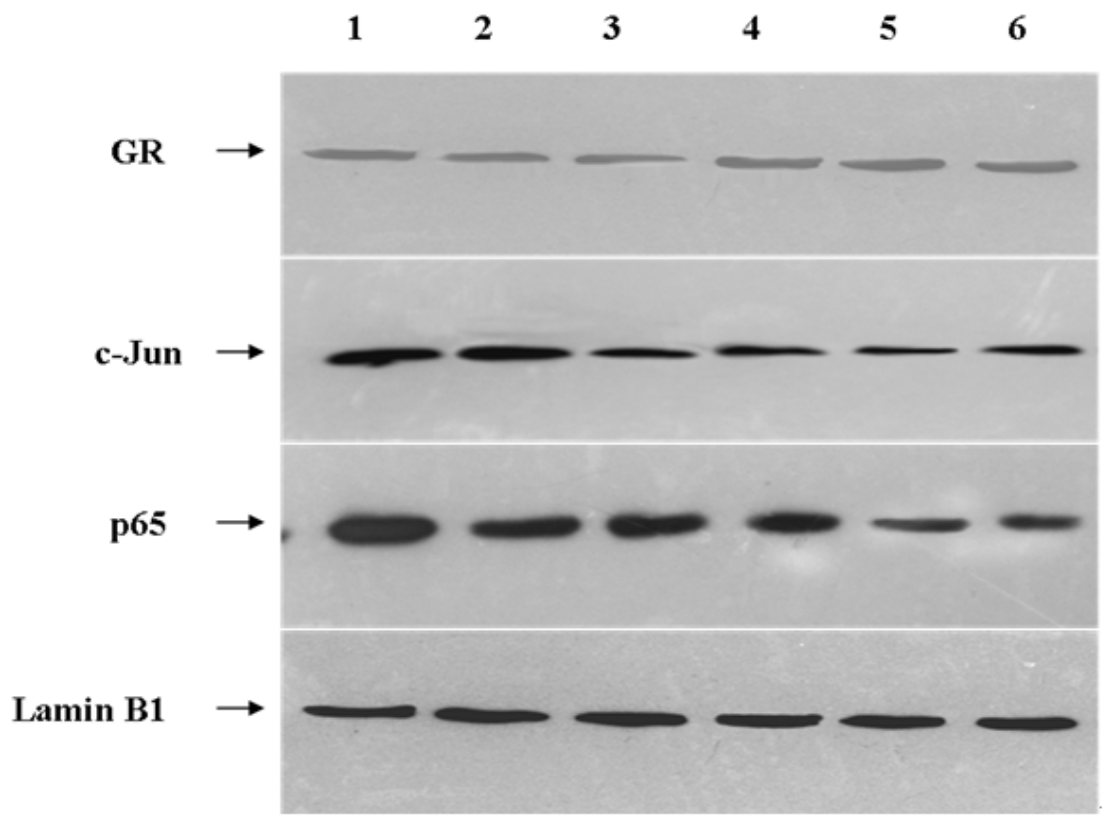

Figure 2: Effect of NCPB on nuclear translocation of GR, c-Jun, p65. Lanes 1-3 represented the protein expressions in the control group at 7, 3 and 1 days after $\mathrm{PH}$, respectively. Lanes 4-6 represented the protein expressions level in NCPB group at 1, 3 and 7 days after $\mathrm{PH}$, respectively

Table 6: Effect of NCPB on the activities of NF-kB and AP-1 of rats after PH $(n=5$, mean \pm SD)

\begin{tabular}{llccc}
\hline Parameter & & Day 1 & Day 3 & Day 7 \\
\hline \multirow{3}{*}{ c-Jun } & Control & $1.21 \pm 0.11$ & $1.75 \pm 0.15$ & $1.52 \pm 0.12$ \\
& NCPB & $1.03 \pm 0.09^{\mathrm{a}}$ & $0.97 \pm 0.08^{\mathrm{b}}$ & $1.07 \pm 0.08^{\mathrm{b}}$ \\
p65 & Control & $1.89 \pm 0.14$ & $1.93 \pm 0.16^{\mathrm{b}}$ & $2.32 \pm 0.22$ \\
\hline
\end{tabular}

${ }^{\mathrm{a}} p<0.05 ;{ }^{\mathrm{b}} p<0.01$, compared with the control

Effect of NCPB on the activities of NF-KB and AP-1 of peritoneal macrophage

From the result of our present investigation (Table 6), we can come to the conclusion that the DNA binding activities of NF-KB and AP-1 of peritoneal macrophage were significantly lower than that in the control group $(p<0.05)$.

\section{DISCUSSION}

Results of our present investigation revealed that NCPB is an effective way to relieve pain in clinic, and we found that the NCPB induced by $0.5 \%$ lidocaine can not only significantly decrease the serum AST and ALT concentrations after $70 \%$ $\mathrm{PH}$ surgery to reduce the hepatocellular damage, but also obviously alleviate the damage of kidney by decreasing the levels of $\mathrm{Cr}$ and BUN. Furthermore, the mechanisms of this protective function of NCPB above may possibly be related to the inhibitory effects of NCPB on stress and inflammatory reaction after severe trauma.

Neuroendocrine responses refers to the stress process started immediately after trauma, and a measurable neuroendocrine response is key for maintaining body homeostasis $[16,17]$, however, SIRS and immune function disorders can be 
induced by over-response. The over-stress reactions after severe trauma mainly manifest as the over-activations of hypothalamic-pituitaryadrenal (HPA) sympathetic-adrenal medulla (SAM). The activation of HPA can be evaluated by levels of serum ACTH and GC. In our present study, we demonstrated that NCPB can significantly decrease the serum concentrations of $\mathrm{GC}$ and $\mathrm{ACTH}$ at all the tested time points compared with the control. What's more, the concentrations of serum NA and $A D$ will be continually increased by over-activation of SAM after trauma, and our results indicated that NCPB treatment can obviously reduce the serum NA and $A D$ levels of $\mathrm{PH}$ rats, compared with the control. All these results above showed that NCPB operation can alleviate significantly the stress response level, and help to maintain homeostasis after trauma. CRP is an acute phase reactive protein $\mathrm{CRP}$, and can partly reflect the level of stress reaction after trauma. Our work demonstrated that NCPB can effectively decrease the serum CRP level, which is another evidence for demonstrating that NCPB can reduce the stress reaction level.

$\mathrm{GC}$ reaction is one of the most important stress reactions of body, and GR is the key point GC. Currently studies reported that severe trauma can induce the down-regulation of GR expression, and GR decrease can possible induce the multiple organ failure (MOF) after trauma [18]. The results of our present study showed that NCPB treatment can significantly increase the level of serum GR, compared to the control. After severe trauma, the secretion of proinflammatory cytokines, including TNF- $\alpha$, IL-1 $\beta$ and IL-6, commonly increased obviously [19]. Our present results demonstrated that NCPB treatment can reduce the concentrations of proinflammatory cytokines, including TNF- $\alpha$, IL-1 $\beta$ and IL-6, which indicated that NCPB can alleviate the function damages of liver and kidney after PH. HMGB1 is an important late inflammatory medium, and plays a crucial role in delayed lethal effect of sepsis [20,21]. In our investigation, NCPB can down-regulate the expression of HMGB1 obviously. Combined with the results of early inflammatory cytokines, we can come to the conclusion that the NCPB can suppress the secretions of cytokines in the whole process of inflammatory reaction.

NF-KB and AP-1 signal transduction paths play the important roles in inflammatory reactions [19]. The p65/p50 heterodimers are the main active pattern of NF-KB, and the degradation of I $\mathrm{KB}$ is the key link of the activation of NF-kB. Under quiescent condition, the heterodimers of NF-KB showed no activity and combined with IKB in the cytoplasm. The degradation of IKB can be induced by some signal stimulus, and then the phosphorylation of the heterodimers of NF-kB induced immediately, resulting in various inflammatory genes' transcription. The results of western blotting showed that NCPB treatment can significantly inhibit the degradation of IKB and decrease the expression of p65, as well as decreasing the nuclear translocation of p65. The expressions of c-Jun are correlated to the activity of AP-1 [22], our work demonstrated that NCPB can decrease the expressions of c-Jun of the macrophages, and suppress its nuclear translocation. In addition, our results also indicated that NCPB can also decrease the DNA binding activities of NF-KB and AP-1. These results indicated that NCPB might block the NF$K B$ and $A P-1$ signal transduction paths, which is also one of the mechanisms that NCPB can inhibit the development of SIRS after PH surgery. $\mathrm{NO}$ is one of the effector molecules for activation of the macrophages to kill pathogenic microorganism and tumors, and is also an important inflammatory medium which plays the pro motive effect in the development of inflammation [23]. Our present study revealed that NCPB can not only significantly suppress the production of NO, but also obviously downregulate the iNOS expressions in the peritoneal macrophage. The activation of NF-KB is the important cause of productions of iNOS by macrophage [24,25], therefore, the result mentioned above also indicated that NCPB might block the NF-kB signal transduction paths.

\section{ACKNOWLEDGEMENT}

This work was supported by Medical Science and Technology Research Key Projects of Chengdu Military Command Area (no. B14010), Hospital Foundation of General Hospital of Chengdu Military Command Area (no. 2011YGB010), Medical Science and Technology Research Projects of Chengdu Military Command Area (no. c12005), and National Natural Science Foundation of China (no. 81171869/H2101).

\section{REFERENCES}

1. Yang C, Yan J, Wang HY, Zhou LL, Zhou JY, Wang ZG, Jiang JX. Effects of bilateral adrenalectomy on the innate immune responses following trauma in rats. Injury 2011; 42: 905-912.

2. Yamakawa $K$, Matsumoto $N$, Imamura $Y$, Muroya $T$, Yamada T, Nakagawa J, Shimazaki J, Ogura $H$, Kuwagata Y, Shimazu T. Electrical vagus nerve stimulation attenuates systemic inflammation and 
improves survival in a rat heatstroke model. PLOS One 2013; 8: e56728.

3. Steinman L. Elaborate interactions between the immune and nervous systems. Nat Immunol 2004; 5:575-581.

4. Bahn BM, Erdek MA. Celiac plexus block and neurolysis for pancreatic cancer. Curr Pain Headache Rep 2013; 17: 310.

5. Erdek M, Halpert DE, González Fernández M, Cohen SP. Assessment of celiac plexus block and neurolysis outcomes and technique in the management of refractory visceral cancer pain. Pain Med 2010; 11: 92-100.

6. Vorenkamp EK, Dahle AN. Diagnostic celiac plexus block and outcome with neurolysis. Tech Region Anesth Pain Manage 2011; 15: 28-32.

7. Wong GY, Schroeder DR, Carns PE, Wilson JL, Martin $D P$, Kinney MO, Mantilla CB, Warner DO. Effect of neurolytic celiac plexus block on pain relief, quality of life, and survival in patients with unresectable pancreatic cancer: A randomized controlled trial. JAMA 2004; 291: 1092-1099.

8. Lausevic Z, Lausevic M, Trbojevic-Stankovic J. Predicting multiple organ failure in patients with severe trauma. Can J Surg 2008; 51: 97-102.

9. Rogers R, Payne JW, Correa AA. A Study of the SIRS with severely traumatized patients. J Pers Assess 2009; 91: 429-438.

10. Li J, Yan HT, Che JX, Bai SR, Qiu QM, Ren L, Pan F, Sun $X Q$, Tian FZ, Li DX, Tang LJ. Effects of Neurolytic Celiac Plexus Block on Liver Regeneration in Rats with Partial Hepatectomy. PLoS ONE 8(9): e73101.

11. National Institute of Health, USA. Public health service policy on humane care and use of laboratory animals; 2002.

12. Higgins GM, Anderson RM. Experimental pathology of the liver. I. Restoration of the liver of the white rat following partial surgical removal. Arch Pathol 1931; 12: 186-202.

13. Hung KC, Hsieh PM, Yang KL, Lin KJ, Chen YS, Hung $\mathrm{CH}$. Effect of thalidomide on the expression of vascular endothelial growth factor in a rat model of liver regeneration. Oncol Lett 2013; 5: 852-856.

14. Jiang $C L$, Zhang $L H, W u$ YF. Establishment of model treated for neurolytic celiac plexus block percutaneously with anhydrous-alcohol in rat. Chin J Pain Med 2008; 14:233-235.
15. Wang J, Zhao J, Li J, Wang F, Su Y. Time-course changes in nuclear translocation of hepatic glucocorticoid receptor in rats after burntrauma and its pathophysiological significance. Shock 2008; 30:747-752.

16. Molina PE. Neurobiology of the stress response: contribution of the sympathetic nervous system to the neuroimmune axis in traumatic injury. Shock 2005; 24:3-10.

17. Yang C, Jiang J. Bilateral regulatory action of corticotrophin-releasing hormone on immunemediated inflammation. Chin J Traumatol 2009; 12: 350-354.

18. Baue AE, Durhamm R, Faist E. Systemic inflammatory response syndrome (SIRS), multiple organ dysfunction syndromes (MODS), multiple organ failure (MOF): are we winning the battle. Shock 1998; 10: 79-89.

19. Li J, Liu YH, Ou S, Dai XM, Wang JP, Su YP. Steroid receptor coactivator-3 differentially regulates the inflammatory response in peritoneal macrophages. Mol Med Report 2012; 5: 1099-1105.

20. Messmer D, Yang H, Telusma G, Knoll F, Li J, Messmer $B$, Tracey KJ, Chiorazzi N. High mobility group box protein 1: an endogenous signal for dendritic cell maturation and Th1 polarization. J Immunol 2004; 173: 307-313.

21. Wang $H$, Ward MF, Sama AE. Targeting HMGB1 in the treatment of sepsis. Expert Opin Ther Targets 2014; 18: 257-268.

22. Liu Z, Jiang $T$, Wang $X$, Wang $Y$. Fluocinolone acetonide partially restores the mineralization of LPS-stimulated dental pulp cells through inhibition of NF-KB pathway and activation of AP-1 pathway. $\mathrm{Br} J$ Pharmacol 2013; 170: 1262-1271.

23. Vodovotz Y, Kim PK, Bagci EZ. Inflammatory modulation of hepatcyte apoptosis by nitric oxide: invivo, invitro, and in silico studies. Curr Mol Med 2004; 4: 753-762.

24. Noguchi S, Nakatsuka M, Konishi H. Nafamostat mesilate suppresses NF-kappaB activation and NO overproduction in LPS-treated macrophages. Int Immunopharmacol 2003; I3: 1335-1344.

25. Richmond A. NF-kB, chemokine gene transcription and tumour growth. Nature Rev Immunol 2002; 2: 664674. 